\title{
Monitoring photolysis and (solar photo)-Fenton of enrofloxacin by a methodology involving EEM-PARAFAC and bioassays: Role of $\mathrm{pH}$ and water matrix
}

\author{
Iván Sciscenko a , Sara Garcia-Ballesteros ${ }^{\mathrm{a}}$, Consuelo Sabater ${ }^{\mathrm{b}}$, María Angeles Castillo ${ }^{\mathrm{b}}$, Carlos Escudero-Oñate ${ }^{\mathrm{c}}$, \\ Isabel Oller ${ }^{\mathrm{d}}$, Antonio Arques ${ }^{\mathrm{a}, *}$ \\ a Departamento de Ingeniería Textil y Papelera, Universitat Politècnica de València (UPV), Plaza Ferrándiz y Carbonell s/n, Alcoy 03801, Spain \\ b Departamento Biotecnología, Universitat Politècnica de València (UPV), Camino de Vera s/n, Valencia 46022, Spain \\ c Norwegian Institute for Water Research (NIVA), Gaustadalléen 21, Oslo 0349, Norway \\ d Plataforma Solar de Almería-CIEMAT, Ctra Senés km 4, Tabernas, Almería 04200, Spain
}

\section{H I G H L I G H T S}

- Enrofloxacin degradation has been studied by photolysis and (photo)Fenton.

- The effect of water constituents, $\mathrm{pH}$ and iron chelation has been determined.

- There is a relationship between antibacterial activity and fluoroquinolone core.

- EEM-PARAFAC is a simple and fast methodology to study a fluoroquinolone degradation.

\section{A R T I C L E I N F O}

\section{Article history:}

Received 19 November 2019

Received in revised form 29 January 2020

Accepted 13 February 2020

Available online 14 February 2020

Editor: Paola Verlicchi

\section{Keywords:}

Photo-Fenton

Direct photolysis

Enrofloxacin

Water matrix effect

Fluorescence excitation-emission matrices

Parallel factor analysis
GRAPHICALA B STRACT

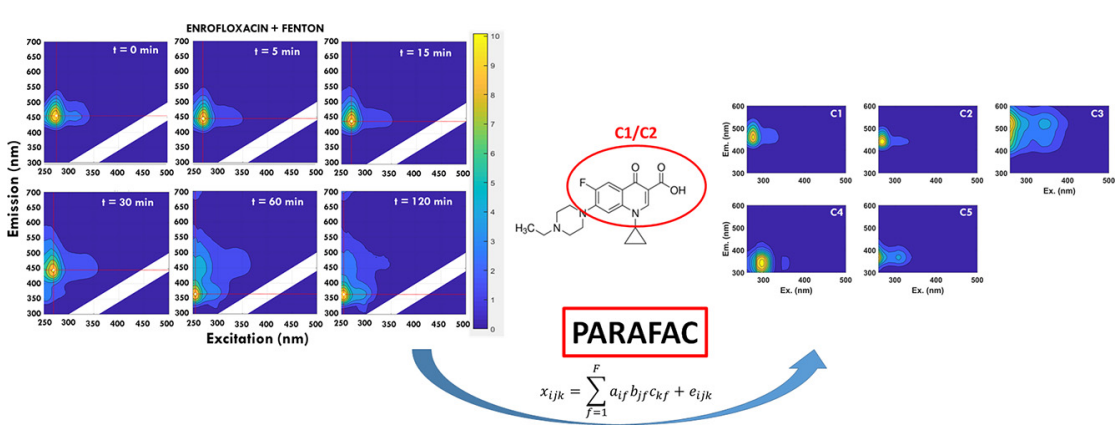

\section{A B S T R A C T}

The degradation of enrofloxacin (ENR) by direct photolysis, Fenton and solar photo-Fenton processes has been studied in different water matrices, such as ultra-pure water (MQ), tap water (TW) and highly saline water (SW). Reactions have been conducted at initial $\mathrm{pH} 2.8$ and 5.0. At $\mathrm{pH}=2.8$, HPLC analyses showed a fast removal of ENR by (solar photo)-Fenton treatments in all studied water matrices, whereas a $40 \%$ removal was observed after 120 min of photolysis. However, TOC measurements showed that only solar photo-Fenton was able to produce significant mineralization ( $80 \%$ after 120 min of treatment); differences between ENR removal and mineralization can be attributed to the release of important amounts of reaction by-products. Excitation-emission matrices (EEMs) combined with parallel factor analysis (PARAFAC) were employed to gain further insight into the nature of these by-products and their time-course profile, obtaining a 5-component model. EEM-PARAFAC results indicated that photolysis is not able to produce important changes in the fluoroquinolone structure, in sharp contrast with (solar photo)-Fenton, where decrease of the components associated with fluoroquinolone core was observed. Agar diffusion tests employing E. coli and S, aureus showed that the antibiotic activity decreased in parallel with the destruction of the fluoroquinolone core.

(c) 2020 The Authors. Published by Elsevier B.V. This is an open access article under the CC BY-NC-ND license (http:// creativecommons.org/licenses/by-nc-nd/4.0/).

Abbreviations: ENR, enrofloxacin; FQs, fluoroquinolones; MQ, MilliQ water; TW, tap water; SW, saline water; EEMs, fluorescence excitation-emission matrices; PARAFAC, parallel factor analysis.

* Corresponding author.

E-mail address: aarques@txp.upv.es (A. Arques). 


\section{Introduction}

Fluoroquinolones (FQs) are broad-spectrum antibiotics extensively used in veterinary and human medicine (Ebert et al., 2011). In fact, according to B. Hamad (2010), FQs are the third-largest group of antibiotics, accounting for $17 \%$ of the global market share. These drugs might enter the environment through different sources such as pharmaceutical industries, hospital and urban wastewaters as well as fish or animal farms (Van Doorslaer et al., 2014). In addition to this, the amount of these antibiotics that are excreted unmetabolized can be estimated in a 70\% (Van Doorslaer et al., 2014). In fact, these chemicals are commonly found in wastewater treatment plants (WWTPs) in concentrations that are usually in the $\mathrm{ng} / \mathrm{L}$ to $\mu \mathrm{g} / \mathrm{L}$ range, but can also be found at higher concentrations (up to $50 \mathrm{mg} / \mathrm{L}$ ) in effluents of drug manufacturing plants (Rakshit et al., 2013). Conventional WWTPs are not able to remove efficiently this family of substances, as percentages of removal of $50-80 \%$ have been reported depending on the molecule (Van Doorslaer et al., 2014), thus constituting an additional route for their incorporation to natural aquatic ecosystems (Guinea et al., 2009). Besides, the FQ core is relatively stable to hydrolysis and thermal decomposition, providing these compounds of large environmental persistence (Babić et al., 2013).

One of the major concerns associated with the presence of antibiotics in the environment is the development of bacterial resistances. The European Food Security Agency has identified FQs among the substances which can generate this risk (ECDC/EFSA/EMA, 2017). Additionally, FQs or their decomposition by-products have shown toxicity towards aquatic organisms if they are not properly eliminated from water bodies (Aristilde et al., 2010; Ebert et al., 2011; Robinson et al., 2005).

In sharp contrast with the low efficiency of the chemical and biotic pathways for FQ removal, photolysis has been described as a major route for the self-remediation of ecosystems containing these substances. Important work has been devoted to study the photodegradation of FQ in different aqueous media (Ge et al., 2018; Zhang et al., 2019). Its photochemical reactivity is attributable to the presence of chromophores which can absorb wavelengths that are within the range of solar radiation reaching the Earth's surface $(300 \mathrm{~nm}<\lambda)$ (Babić et al., 2013). Different mechanisms, namely direct and indirect photolysis as well as self-sensitized processes, have been described for FQs (Ge et al., 2010; Li et al., 2011).

Natural processes are not always strong enough to treat effluents polluted with antibiotics, but some photochemical advanced oxidation processes (AOPs) have been shown to be useful to treat FQ (Guinea et al., 2009; Feng et al., 2018; Feng et al., 2016; Van Doorslaer et al., 2013; Sun et al., 2019). AOPs are able to generate powerful transitory reactive species, mainly hydroxyl radicals $(\cdot \mathrm{OH})$ (Glaze et al., 1987; Legrini et al., 1993), but other species can also be involved (An et al., 2010). In particular, Fenton process is able to produce reactive species, such as $\bullet \mathrm{OH}$ and highly oxidized iron species, using iron salts as catalysts to improve the oxidizing ability of $\mathrm{H}_{2} \mathrm{O}_{2}$, following a rather complex mechanism that is still to be completely elucidated (Pignatello et al., 2006). The photo-Fenton process consists in an enhancement of the Fenton reaction upon irradiation with UV or visible light, and hence sunlight can be employed with the economic and ecological advantages that they involve (Malato et al., 2009). Some examples are available in literature on the treatment of FQs by Fenton (Gupta and Garg, 2018; Villegas-Guzman et al., 2017) and photo-Fenton (Michael et al., 2013; Villegas-Guzman et al., 2017).

However, some research is still needed on the use of (photo)-Fenton to FQs removal. In particular, the effect of operational variables such as $\mathrm{pH}$ and or salinity has not been deeply evaluated. As FQs are commonly employed in marine fish farms (Aufartová et al., 2017; Buschmann et al., 2012; He et al., 2012; Robinson et al., 2005), the presence of high amounts of chlorides can drive undesired secondary reactions, decreasing the efficiency of the process (Pignatello, 1992; Buxton et al., 1988) and/or leading to the formation of chlorinated by-products (Calza et al., 2005; Liu et al., 2009). Hence, further research is required to determine the extent of such reactions and to rule out possible undesirable side effects. On the other hand, exploring the performance of FQs degradation at mild $\mathrm{pHs}$ becomes of paramount relevance in real-case scenarios (Santos-Juanes et al., 2017). In addition to this, complete mineralization of FQs is a challenging goal to be reached (Gupta and Garg, 2018), since reaction by-products remain in the system, and their nature has to be unveiled and their biocompatibility assessed.

In this work, we report on the degradation of enrofloxacin (ENR), a common FQ developed to be employed in animals (Idowu and Peggins, 2004), also related to ciprofloxacin (a FQ used in human medicine) (Aresta et al., 2019; Ebert et al., 2011; García Ovando et al., 1999). Photolysis and (solar photo)-Fenton have been tested under simulated sunlight at different pHs (2.8 and 5.0) and using three aqueous matrices, namely Milli-Q (MQ), tap water (TW) and highly saline water (SW), following ENR removal by HPLC and mineralization by TOC analysis. However, these tools provide only partial information on the behaviour of the organic matter along the process and on the nature of the byproducts that are released. Hence, implementation of a simple methodology to obtain major trends on by-products formation is needed. In this context, chemometric tools are gaining momentum, as they can extract valuable information from raw complex data (Alves and Poppi, 2013; Boughattas et al., 2019; Karoui and De Baerdemaeker, 2007; Trawiński and Skibiński, 2018). In this sense, and taking advantage of the photophysical properties of FQ-type molecules, fluorescence excitation-emission matrices (EEMs) with the multi-way method, parallel factor analysis (PARAFAC), have been selected to study the ENR degradation. EEM-PARAFAC is based on the decomposition of the measured EEMs into their underlying chemical components, which can be associated with families of compounds bearing similar chromophores (García et al., 2019). Due to this reason, it has been mainly employed in the organic fraction characterization of complex water samples containing dissolved organic matter (Cory and McKnight, 2005; Stedmon et al., 2003; Tang et al., 2020) and also to monitor its changes (Li et al., 2014; Ly et al., 2018). Although it cannot reach the detail of sophisticated HPLC-HRMS techniques, it is easy, relatively cheap and non-time consuming. As far as we know, this is the first time that a FQ degradation is followed in time-course experiments using EEM-PARAFAC as until now, only a few examples of application of this technique on FQs can be found in chemometrics (De la Peña et al., 2003; Vosough et al., 2015) or to describe chemical interactions of these substances ( $\mathrm{Ni}$ et al., 2009). In addition, there are very few examples on the application of this technique to gain further insight into the efficiency of advanced oxidation processes (Carabajal et al., 2017; García et al., 2019; GarcíaBallesteros et al., 2016).

Finally, bioassays based on the inhibition halo of E. coli and S. aureus have been used to estimate the antibacterial activity of the effluents derived from the different treatments, relating the results with all the above mentioned methodologies.

\section{Experimental section}

\subsection{Reagents}

High purity ENR ( $>99 \%)$, purchased from Sigma-Aldrich, was used in all the experiments. $\mathrm{Na}_{2} \mathrm{SO}_{3}$ anhydride, $\mathrm{FeSO}_{4} \cdot 7 \mathrm{H}_{2} \mathrm{O}, \mathrm{H}_{2} \mathrm{O}_{2}(33 \% \mathrm{w} / \mathrm{v})$, ascorbic acid, 1,10-phenantroline 1-hydrate, $\mathrm{NH}_{4} \mathrm{VO}_{3}, \mathrm{NaCl}, \mathrm{H}_{2} \mathrm{SO}_{4} 96 \%$, and UHPLC grade methanol and acetonitrile were obtained from AppliChem-Panreac. 80\% formic acid was purchased from VWR Chemicals. Ultra-pure water was prepared with a Millipore system (MQ). Catalase from bovine liver (lyophilized powder 2000-5000 units/ mg protein) was purchased from Sigma-Aldrich. Tap water employed in the experiments was obtained from the urban supply network of Alcoy (Spain) and had the following characteristics: $\mathrm{pH}=7.4$, inorganic carbon $=52 \mathrm{mg} / \mathrm{L}$, conductivity $=510 \mu \mathrm{S} / \mathrm{cm},\left[\mathrm{Cl}^{-}\right]=27.8 \mathrm{mg} / \mathrm{L}$, 
$\left[\mathrm{SO}_{4}^{2-}\right]=33.3 \mathrm{mg} / \mathrm{L}$, water hardness $=142 \mathrm{mg} / \mathrm{L}$ of $\mathrm{CaCO}_{3}$. Saline water was prepared by dissolving $30 \mathrm{~g}$ of $\mathrm{NaCl}$ in $1 \mathrm{~L}$ of tap water.

Agar diffusion tests were made using Escherichia coli CECT 101 strain for MQ and TW assays; because of the incompatibility of E. coli with highly saline media, the halotolerant Staphylococcus aureus CECT 435 for the SW ones. Tryptone soya broth and Mueller-Hinton broth were both provided by Scharlau.

\subsection{Reactions}

Reactions were carried out in cylindrical open glass reactors (total volume of $500 \mathrm{~mL}$ ). For each experiment, the reactor was loaded with $250 \mathrm{~mL}$ of ENR solution (initial concentration of $25 \mathrm{mg} / \mathrm{L}$ ), also containing $5 \mathrm{mg} / \mathrm{L}$ of $\mathrm{Fe}$ (II) (using $\mathrm{FeSO}_{4} \cdot 7 \mathrm{H}_{2} \mathrm{O}$ as the source of iron), prepared with the desired water matrix, MQ TW or SW. Initial pH was adjusted to 2.8 or 5.0 by dropwise addition of $\mathrm{H}_{2} \mathrm{SO}_{4} 0.5 \mathrm{M}$ and/or $\mathrm{NaOH} 1 \mathrm{M}$. For the (solar photo)-Fenton experiments, the stoichiometric amount of $\mathrm{H}_{2} \mathrm{O}_{2}$ to mineralize ENR was added $(125 \mathrm{mg} / \mathrm{L})$; this is a useful procedure commonly employed to normalize the amount of hydrogen peroxide added to the reaction medium and to ensure that the process is not stopped because of the exhaustion of hydrogen peroxide (Bernabeu et al., 2011; Gomis et al., 2015). When necessary, irradiations were performed with a solar simulator (Oriel Instrument) equipped with a highpressure Xe short arc lamp (Ushio UXL-302-0).

Experiments were run for $120 \mathrm{~min}$ and samples were taken periodically and processed differently depending on the type of analysis. In the case of HPLC and EEMs measurements, $5 \mathrm{~mL}$ of each sample were taken from the solution, and $50 \mu \mathrm{L}$ of methanol were added to quench the excess of hydrogen peroxide, thus stopping the reaction (Gomis et al., 2014; Pignatello et al., 2006). Then $50 \mu \mathrm{L}$ of $\mathrm{H}_{2} \mathrm{SO}_{4} 5 \mathrm{M}$ were added to each sample in order to ensure the acidic $\mathrm{pH}$, due to the $\mathrm{pH}$ dependence of the absorption and fluorescence spectra of ENR (Lizondo, 1997). For TOC analysis, $\mathrm{Na}_{2} \mathrm{SO}_{3}$ was used instead of methanol to deal with the excess of $\mathrm{H}_{2} \mathrm{O}_{2}$ in order to avoid interferences caused by the addition of extra organic substances. Finally, in the case of the bioassays, samples were previously adjusted to $\mathrm{pH} 7.0( \pm 0.5)$ with $\mathrm{NaOH} 1 \mathrm{M}$, and the remaining hydrogen peroxide was consumed by addition of catalase enzyme.

Dark controls were performed with and without iron observing no changes in the concentration of ENR. Controls with $\mathrm{H}_{2} \mathrm{O}_{2}$ without iron, and with and without irradiation, were also performed. $\mathrm{H}_{2} \mathrm{O}_{2}$ in the dark was not able to degrade ENR.

\subsection{Chemical analysis}

ENR concentration was determined using HPLC. The equipment consisted of a Hitachi Chromaster, equipped with a pump model 5110 a UV/Vis detector (model 5410), and oven (model 5310) and an autosampler (5210 model). A C18 Machery-Nagel column Nucleodur$\pi^{2} 5 \mu \mathrm{m}$ was used as stationary phase and an isocratic flow of $0.25 \mathrm{~mL} /$ min of formic acid $0.1 \mathrm{M}$ and acetonitrile (80:20) was used as eluent The oven was set at $40{ }^{\circ} \mathrm{C}$ and the detection was performed at $275 \mathrm{~nm}$. Mineralization analyses were performed in a Shimadzu TOC$\mathrm{V}$ equipment with ASI-V autosampler.

EEMs were measured with a fluorimeter Photon Technology International (PTI) QuantaMaster 400, equipped with a Xe arc lamp. The explored excitation range was $250-500 \mathrm{~nm}$ (at $5 \mathrm{~nm}$ intervals), whereas the emission range was $300-700 \mathrm{~nm}$ (also at $5 \mathrm{~nm}$ intervals). A Hitachi-UH5300 spectrophotometer was employed to correct the inner filter effect (250-700 nm). The same spectrophotometer was used to measure the dissolved total iron concentration according to the ISO 6332:1988 standardized method and also to monitor $\mathrm{H}_{2} \mathrm{O}_{2}$ following a modification of the metavanadate method reported by Nogueira et al. (2005).

For the agar diffusion tests, bacteria (E. coli for MQ and TW, and S. aureus for SW) were previously grown up in a nutrient media for
$18 \mathrm{~h}$. Then, colonies were inoculated in a Tryptone soya broth, having a suspension of 0.5 units in McFarland scale. A sterile cotton swab was used to pick bacterial suspension and spread it on the surface of the Mueller-Hinton agar in the Petri dish. Afterwards, $0.85 \mathrm{~cm}$ wells were made and filled with $100 \mu \mathrm{L}$ of the sample. Finally, the Petri dishes were incubated at $37{ }^{\circ} \mathrm{C}$ for $24 \mathrm{~h}$, and then the inhibition halos were read.

\subsection{Mathematical calculations}

PARAFAC was applied in order to analyze the underlying signals present in the obtained EEM. For this purpose, 110 EEMs, obtained from sampling ENR solutions after different periods of treatment (described in Section 2.2) were recorded. PARAFAC was conducted using MATLAB 2018b with the graphical user interface EEMlab (Micó et al., 2019), which employs the routines of drEEM toolbox for the pretreatment and analysis of the data (Murphy et al., 2013).

Briefly, the procedure, which is explained in detail in the works of Bro (1997) and Bro and Kiers (2003), consists in the following key steps: EEMs were first normalized by water Raman first order scattering signal ( $350 \mathrm{~nm}$ excitation wavelength and $365-450 \mathrm{~nm}$ for emission) in order to reduce error of the power lamp decay over time due to usage. Inner-filter effects were handled by uploading the absorbance spectra of each sample. MQ TW and SW in the presence of $50 \mu \mathrm{L}$ of methanol and $50 \mu \mathrm{L}$ of $5 \mathrm{M} \mathrm{H}_{2} \mathrm{SO}_{4}$ solution were also recorded to perform the corresponding blank-subtractions to each sample. Regions affected by Rayleigh and Raman scattering were removed and data in those domains were estimated by interpolation from either sides of the bands. The correct number of components was assessed according to the chemical consistency of the obtained data, the evaluation of the distribution of the residuals and the core consistency diagnostic (CCD).

\section{Results and discussion}

\subsection{ENR removals in different media}

The degradation of ENR was studied under photolysis, Fenton and solar photo-Fenton in MQ water at pH 2.8 and 5.0. Plots of the normalized concentration of ENR vs. time are presented in Fig. 1. It can be observed that, at the same $\mathrm{pH}$, ENR removal was faster in photo-Fenton, followed by Fenton and finally photolysis. The $\mathrm{pH}$ effect was not important for photolysis, but (photo)-Fenton was more efficient at $\mathrm{pH}=2.8$ than 5.0. This should be attributed to precipitation of iron (III) at $\mathrm{pH}$ above 3 by formation of hydroxides that are not able to participate in the Fenton process (Pignatello et al., 2006). However, it is remarkable that ENR removal was still fast at $\mathrm{pH}=5.0$ by means of solar photoFenton (complete elimination of $25 \mathrm{mg} / \mathrm{L}$ of ENR in $<60 \mathrm{~min}$ ). In fact,

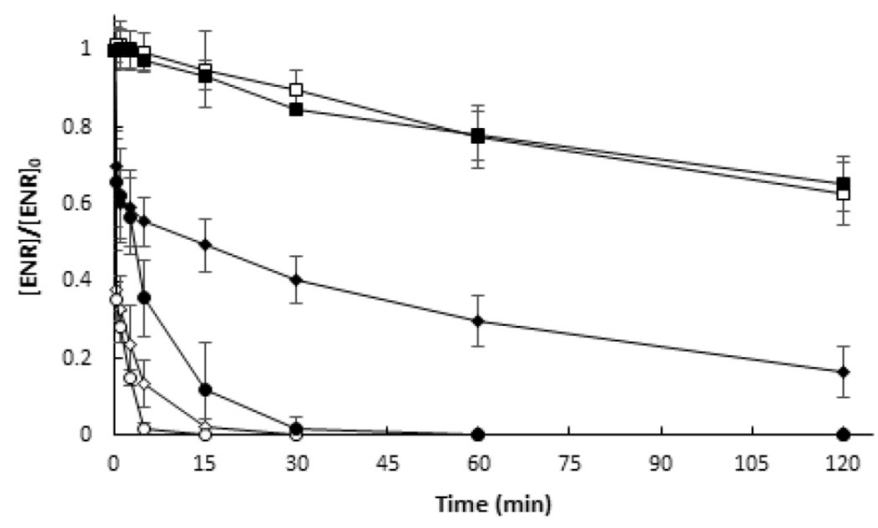

Fig. 1. ENR degradation profiles in Milli-Q water: photolysis at $\mathrm{pH}=5(\boldsymbol{\square})$; photolysis at $\mathrm{pH}=2.8(\square)$; Fenton at $\mathrm{pH}=5(\diamond)$; Fenton at $\mathrm{pH}=2.8(\diamond)$, photo-Fenton at $\mathrm{pH}=5(\bullet)$ and photo-Fenton at $\mathrm{pH}=2.8(\mathrm{O})$. 
complexation of iron is one of the strategies followed to keep iron active at mild pH (Santos-Juanes et al., 2017; Pignatello et al., 2006; De Luca et al., 2014). This effect has been observed in some compounds such as phenols, where complexation of iron by these substances shifted the optimum pH to values close to 4 (García-Ballesteros et al., 2016). Indeed, formation of complexes between FQs and iron has been observed and described in literature (Cuprys et al., 2018; Efthimiadou et al., 2008; Turel, 2002) and their role in Fenton and related processes has been reported (Chen et al., 2017; Giri and Golder, 2019). Hence, it can be proposed that ENR forms photoactive complexes with iron to explain the good efficiency of photo-Fenton at $\mathrm{pH}=5.0$. An indirect evidence is that the amount of iron remaining in the solution after photolysis remained nearly constant at $5 \mathrm{mg} / \mathrm{L}$ because of the formation of the ENR-Fe complex, in sharp contrast with the photo-Fenton experiment, where a continuous decrease in iron concentration was observed, in agreement with the destruction of ENR (in the absence of the complexant, precipitation of iron occurs).

Water matrix effect in the ENR degradation was also studied, performing the experiments also in TW and SW. Obtained removal percentages in these conditions at both studied pHs, 2.8 and 5.0, for direct photolysis presented no significant differences with the ones obtained in MQ, being systematically in the range $20-40 \%$ after 120 min; therefore, water constituents do not have big influence regarding direct irradiation of the compound. On the contrary, a matrix effect can be observed for Fenton and photo-Fenton, as shown in Fig. 2a and b. In those cases the fastest ENR removals were obtained in SW followed by TW and then in MQ. This primary disappearance of the parent product could be attributed to some reactivity of chlorinated radicals. As a matter of fact, in solutions containing high concentrations of chlorides, $\mathrm{Cl}$ • and $\mathrm{Cl}_{2}{ }^{-}$- can play an important role, as they can be formed either by direct reaction between $\cdot \mathrm{OH}$ and $\mathrm{Cl}^{-}$, or by photolysis of iron-chloride complexes, such as $\mathrm{FeCl}^{+}, \mathrm{FeCl}^{2+}$ and $\mathrm{FeCl}_{2}^{+}$(De Laat and Le, 2006; Machulek Amilcar et al., 2007; Soler et al., 2009). This is in agreement

a)

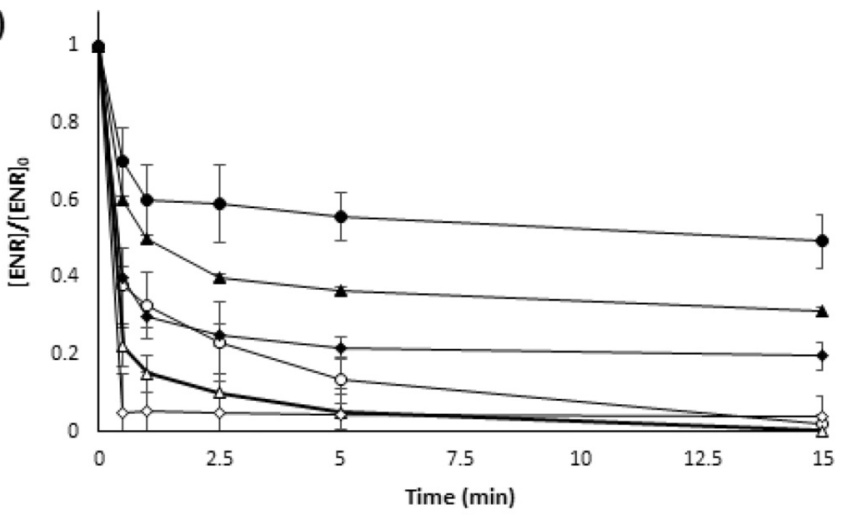

b)

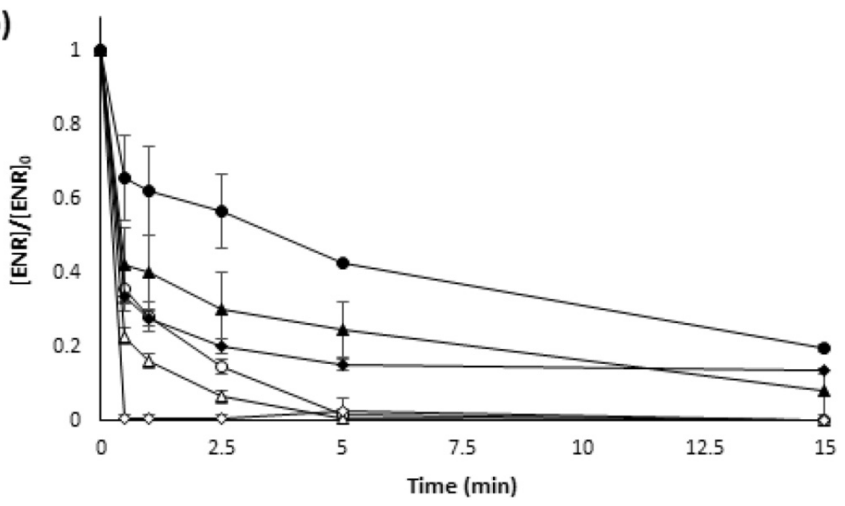

Fig. 2. ENR removal in different aqueous media for a) Fenton, b) solar photo-Fenton. SW at $\mathrm{pH}=5(\diamond) ; \mathrm{SW}$ at $\mathrm{pH}=2.8(\diamond) ; \mathrm{TW}$ at $\mathrm{pH}=5(\boldsymbol{\Delta}) ; \mathrm{TW}$ at $\mathrm{pH}=2.8(\Delta) ; \mathrm{MQ}$ at $\mathrm{pH}=5$ (๑) and MQ at $\mathrm{pH}=2.8(\mathrm{O})$. with the lower $\mathrm{H}_{2} \mathrm{O}_{2}$ consumption observed in $\mathrm{SW}$ in comparison with the other two water matrices (see Fig. S1). As a matter of fact, higher consumptions have been detected at $\mathrm{pH}=2.8$ than at 5.0 , in agreement with the better performance of photo-Fenton at former conditions.

\subsection{Fluorescence spectroscopy analysis}

The removal of ENR should not be related straightforward with a detoxification of the solution, as other products (even more toxic than parent compounds) might be released into the solution. To evaluate the amount of organics in the solution, total organic carbon (TOC) was determined after 120 min of solar photo-Fenton in all three matrices at $\mathrm{pH}=2.8$ and 5.0. Interestingly, higher mineralization was reached for solar photo-Fenton at $\mathrm{pH}=2.8$ for both $\mathrm{MQ}$ and $\mathrm{TW}$ with values of ca. $80 \%$, followed by the same matrices at $\mathrm{pH}=5.0$ (mineralization slightly above $50 \%$ ), whereas for SW, mineralization was below $20 \%$ at both pHs. Finally, in the case of the control of $\mathrm{H}_{2} \mathrm{O}_{2}$ with irradiation in MQ water, the observed ENR removal did not result in any mineralization.

The next step is gaining further insight into the nature of the organic matter present in the solution. However, for such complex samples conventional chromatography cannot be applied and gross parameters such as total organic carbon or chemical oxygen demand provide scarce information. For this reason, EEMs were measured, as they can give the fingerprints of major chromophores present in the reaction mixture. Fig. 3 shows the EEMs recorded for the photolysis, Fenton and solar photo-Fenton of ENR in MQ at $\mathrm{pH}=2.8$. It can be observed that photolysis was not able to produce significant changes in EEMs, which could be attributed to the persistence of the FQ core. On the contrary, changes in the EEMs can be observed for (photo)-Fenton, being faster for photoFenton than for Fenton. These observations might indicate that those processes are able to destroy the FQ moiety.

In order to gain further insight into the behaviour of the FQs along the process, PARAFAC was applied to the data set containing all the measured EEMs obtained in this work, namely photolysis, Fenton and photo-Fenton, in all three water matrices and both $\mathrm{pH}$ values (see Section 2.4 for details). A model consisting in 5 components was chosen, as in comparison with the models with fewer components, it was the only one able to resolve all the overlapped fluorescence signals appearing in the measured EEMs and, on the other hand, showed a higher chemical consistency when compared to those considering more components (see Fig. S2), that shows the CCD behaviour vs. the number of modelled components, were an abrupt change in the tendency of the curve was observed beyond the 5-model (Bro and Kiers, 2003).

In Fig. 4 the fingerprints for the 5-component model are shown. C1 can be related with the parent pollutant, ENR, although other byproducts containing the $\mathrm{FQ}$ core can contribute. $\mathrm{C} 2$ presents very similar fingerprint as $\mathrm{C} 1$, but with a small shift in the maximum position to lower values in the emission axis; thus $\mathrm{C} 2$ is also supposed to belong to FQ type molecules. On the other hand, C3, C4 and C5 appear only in those experiments where the FQ structure is destroyed (Fenton and solar photo-Fenton, at $\mathrm{pH}=2.8$ with MQ and TW), and hence, they should be associated to different families of by-products generated by the strong oxidation of FQ.

Certainly, one of the most important subjects to be addressed is the removal of the FQ moiety, since the antibiotic properties could be associated to this functional group. Hence, the remaining amount of FQ might be considered as a preferred method to assess the efficiency of the photochemical process than just the disappearance of ENR followed by HPLC. Fig. 5 shows the plot of $\mathrm{C} 1+\mathrm{C} 2$ vs. time; as $\mathrm{C} 1$ and $\mathrm{C} 2$ are assigned to compounds with the FQ moiety, the sum of their scores could be associated with the remaining amount of FQ in the medium.

Comparison of Figs. 1 and 5 shows that, in general, similar trends can be found between $\mathrm{C} 1+\mathrm{C} 2$ and ENR relative amount shown by HPLC: a) No destruction of the FQ in photolysis experiments, in line with the 

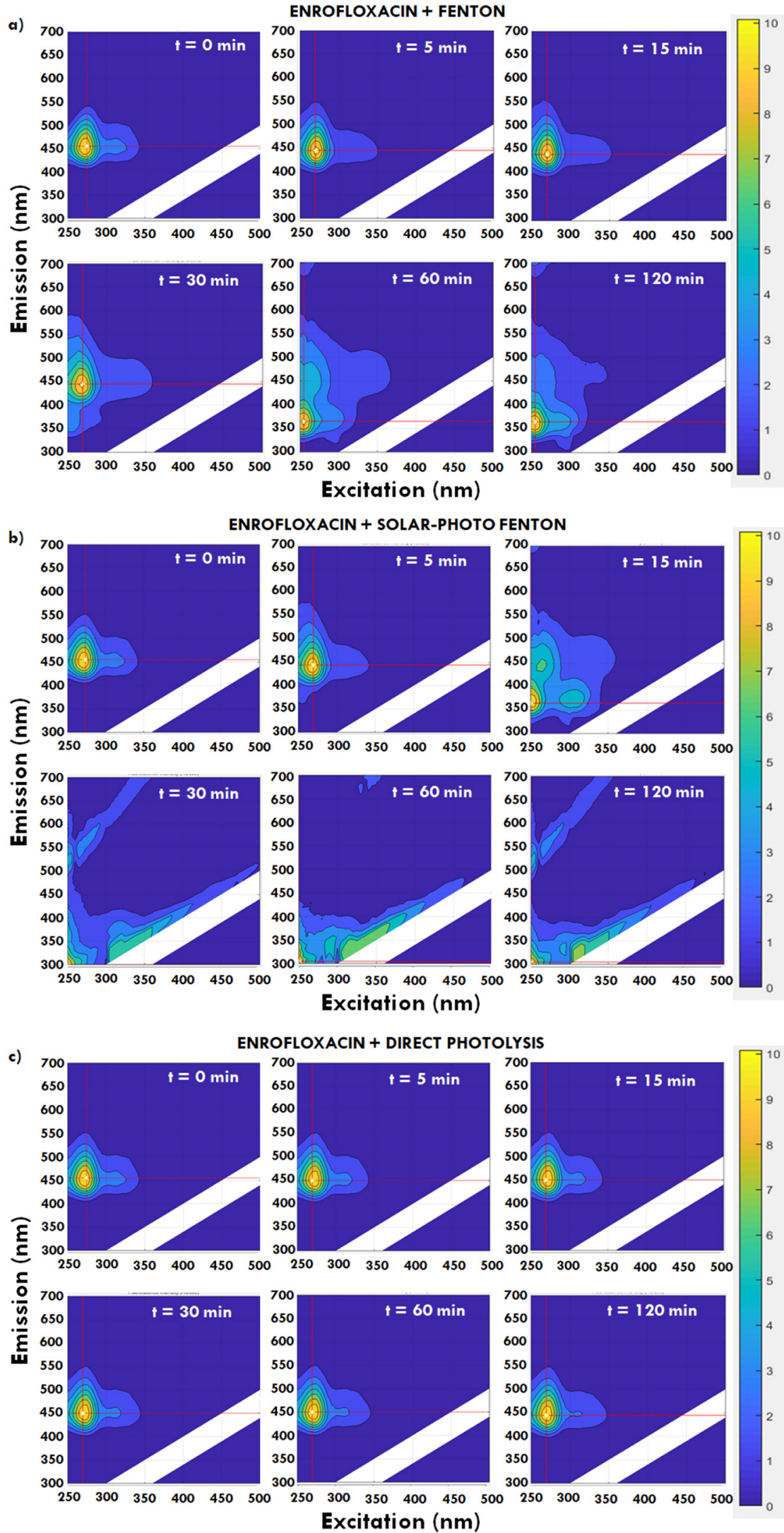

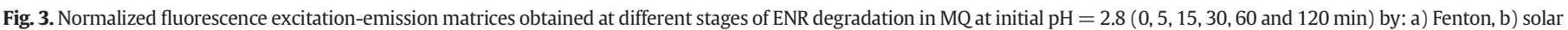
photo-Fenton and c) direct photolysis. 

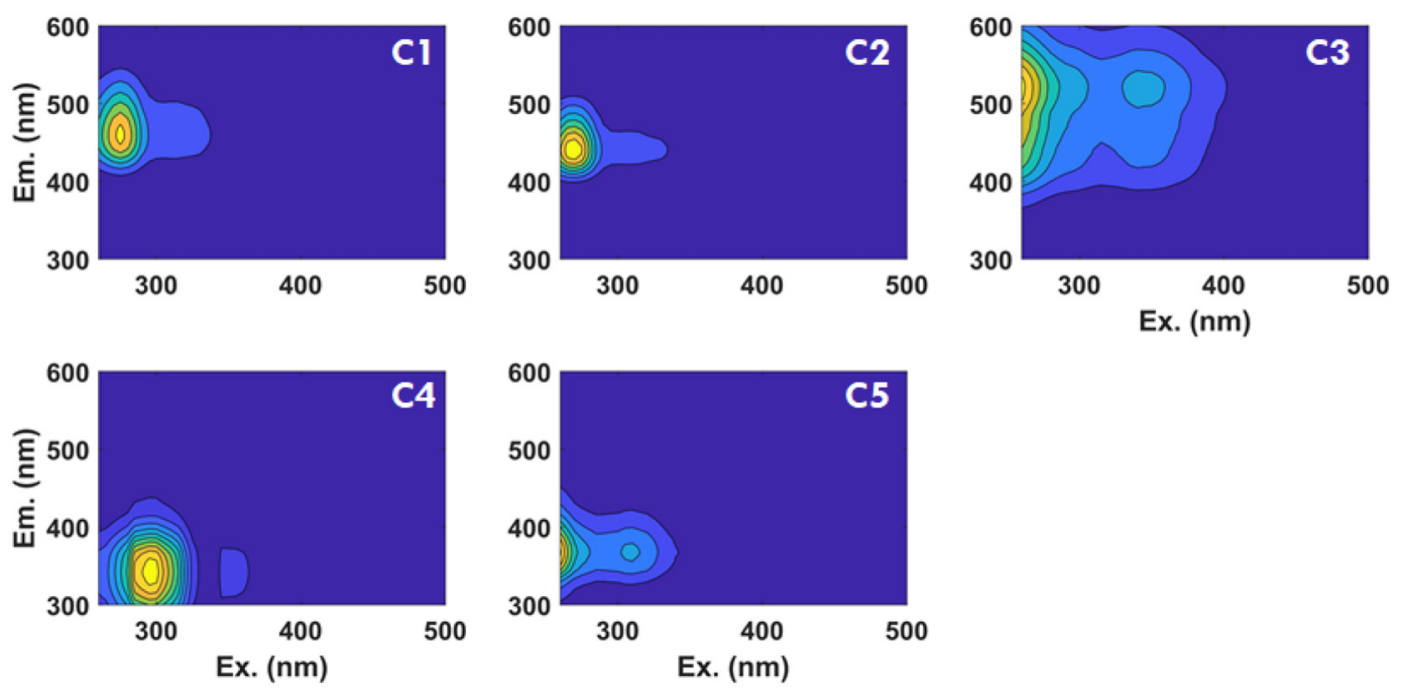

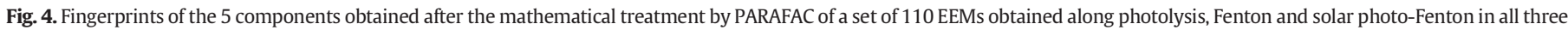
water matrices and at $\mathrm{pH} 2.8$ and 5.0.

low removal of the parent pollutant; b) some decrease in the $\mathrm{C} 1+\mathrm{C} 2$ components was reached in the other cases following the trend: Fenton at $\mathrm{pH}=5.0<$ photo-Fenton at $\mathrm{pH}=5.0=$ Fenton at $\mathrm{pH}=2.8<$ photoFenton at $\mathrm{pH}=2.8$. This behaviour can be understood by considering that although photolysis is able to remove ENR, it cannot produce important changes in the fluoroquinolone structure (Babić et al., 2013; Ge et al., 2018; Zhang et al., 2019) and only stronger oxidation agents (e.g. • OH) efficiently attack the fluoroquinolone core (An et al., 2010).

It is also interesting to test according to this parameter the effect of the water matrix. Results obtained for photo-Fenton can be observed in Fig. 6. A comparison of Figs. 2 and 6 shows significant differences, involving that the removal of ENR might not involve the elimination of the FQ moiety. Reactions carried out in SW resulted in a very fast removal of ENR but the presence of $\mathrm{C} 1$ and $\mathrm{C} 2$ after $120 \mathrm{~min}$, indicates that the reaction resulted in the release of by-products still having the FQ structure. On the contrary, in MQ and TW, important changes in the structure of the molecule have occurred and all the fluoroquinolonic intermediates were removed after $15 \mathrm{~min}$ at $\mathrm{pH}=2.8$ and at $30 \mathrm{~min}$ at $\mathrm{pH}=5.0$. This is in line with TOC measurements (where the lowest mineralization percentage was obtained in the case of SW at both studied pHs) and can be explained if (photo)-Fenton in the presence of high concentration of chlorides results in the formation of less reactive species, that can destroy ENR but not the FQ core.

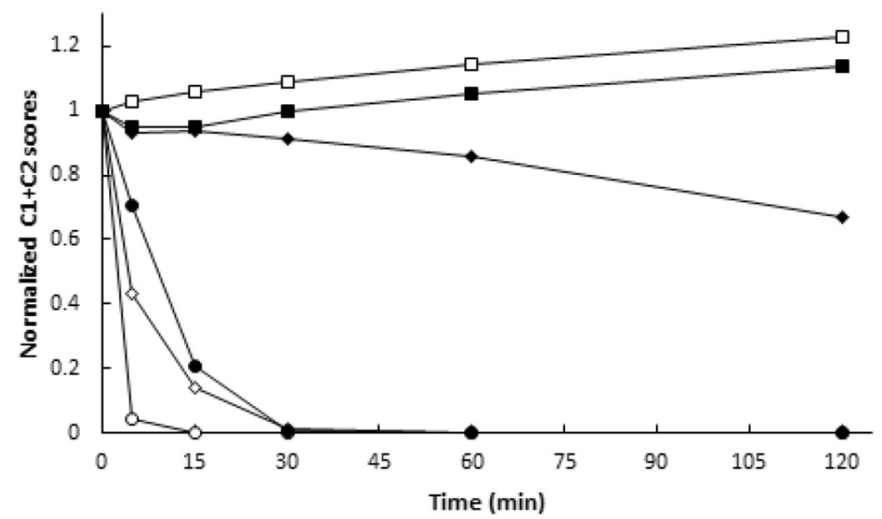

Fig. 5. Plot of the flouroquinolonic components obtained in the EEM-PARAFAC model (C1 and $\mathrm{C2}$ ) vs. time in MQ water. Photolysis at $\mathrm{pH}=5(\boldsymbol{\square})$; photolysis at $\mathrm{pH}=2.8(\square)$; Fenton at $\mathrm{pH}=5(\diamond)$; Fenton at $\mathrm{pH}=2.8(\diamond)$, photo-Fenton at $\mathrm{pH}=5(\bullet)$ and photoFenton at $\mathrm{pH}=2.8(\mathrm{O})$.

\subsection{Agar diffusion tests}

In order to check the residual antibiotic properties of the FQ treated solution, inhibition halo tests were performed. In line with expectations, these bioassays showed an almost identical behaviour as the fluoroquinolonic compounds, as shown by the $\mathrm{C} 1+\mathrm{C} 2$ components decay in EEM-PARAFAC. Fig. 7 shows results in MQ water for photolysis and (photo)-Fenton at $\mathrm{pH}=2.8$ and 5.0. The inhibition halo disappeared after 15 and $30 \mathrm{~min}$ for solar photo-Fenton and Fenton processes respectively in MQ at $\mathrm{pH} 2.8$, whereas in photolysis the inhibition halo remained constant even after 120 min of irradiation and not notable decrease of inhibition halos for Fenton performed at pH 5.0 was seen. This might indicate that the destruction of the FQ structure is needed to eliminate the antibiotic properties (Ge et al., 2018, 2015; Rosen et al., 1989).

The same trend can be found in the photo-Fenton treatment under different experimental conditions (Fig. 8). The decay in the antibacterial activity is in agreement with the data obtained with the EEM-PARAFAC analysis of the FQ components: the degradation was faster at $\mathrm{pH}=2.8$ than at $\mathrm{pH}=5.0$ and the process driven at MQ water was more efficient than when salts were present. Finally, to verify if the possible chlorinated by-products formed in SW matrices were even more toxic than the original ENR, additional Aliivibrio fischeri experiments were

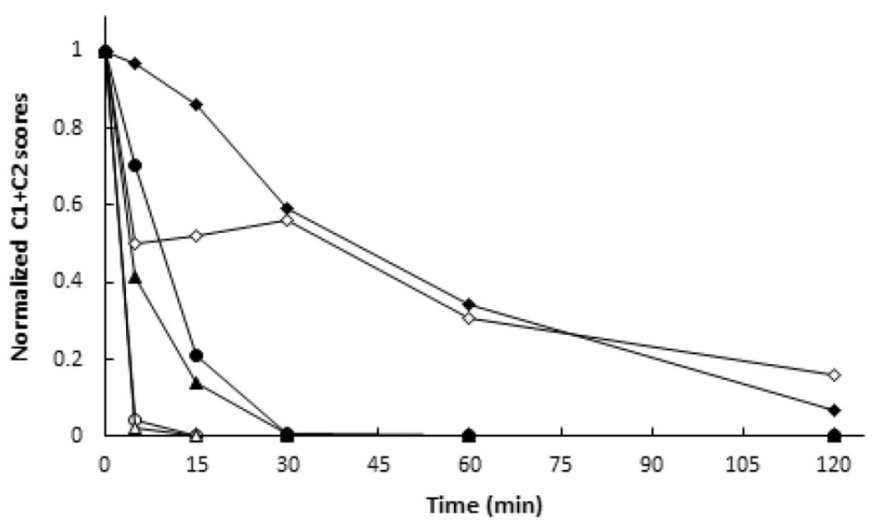

Fig. 6. Elimination of flouroquinolonic components ( $\mathrm{C} 1$ and $\mathrm{C} 2$ ) obtained in the EEMPARAFAC model vs. time with solar photo-Fenton at different water matrices. SW at $\mathrm{pH}=5(\diamond)$; SW at $\mathrm{pH}=2.8(\diamond) ; \mathrm{TW}$ at $\mathrm{pH}=5(\boldsymbol{\Delta})$; TW at $\mathrm{pH}=2.8(\Delta) ; \mathrm{MQ}$ at $\mathrm{pH}=5(\bullet)$ and $\mathrm{MQ}$ at $\mathrm{pH}=2.8(\mathrm{O})$. 


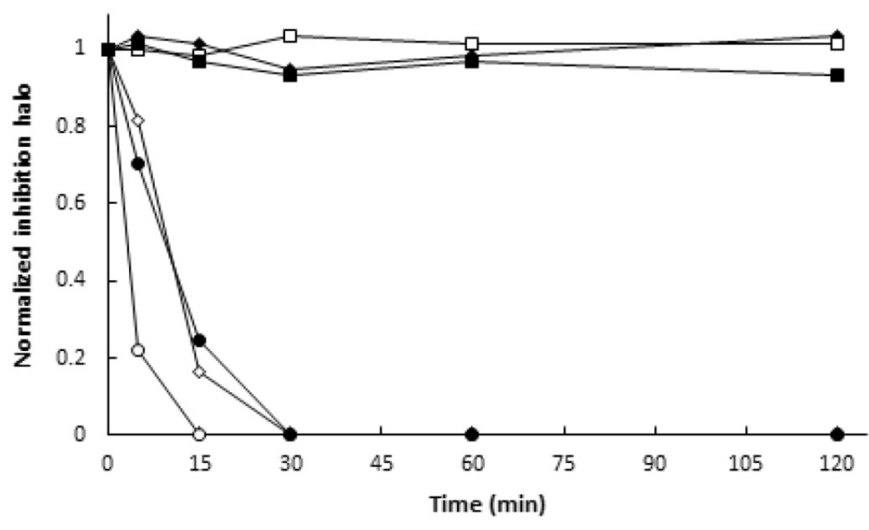

Fig. 7. Antibacterial activity behaviour obtained with $E$. coli for the different tested processes in MQ at both studied pHs. Photolysis at $\mathrm{pH}=5(\boldsymbol{\square})$; photolysis at $\mathrm{pH}=2.8$ $(\square)$; Fenton at $\mathrm{pH}=5(\diamond)$; Fenton at $\mathrm{pH}=2.8(\diamond)$, photo-Fenton at $\mathrm{pH}=5(\bullet)$ and photo-Fenton at $\mathrm{pH}=2.8(\mathrm{O})$.

performed, showing also a decay of toxicity with the reaction time (approximately $50 \%$ decrease in the toxicity measured according this assay after 120 min of photochemical process).

\section{Conclusions}

Solar photo-Fenton process resulted to be more efficient than photolysis and Fenton (according to ENR removal, mineralization percentage and inhibition halo decrease). Regarding the effect of the initial $\mathrm{pH}$, higher removals were obtained at $\mathrm{pH} 2.8$ rather than at $\mathrm{pH} 5.0$. However, the good performance of solar photo-Fenton at $\mathrm{pH} 5$, probably due to iron complexation, requires further research. Similar performances have been observed in MQ and TW, with fast total removal and high mineralization achieved in both cases. On the contrary, in SW, the fast ENR removal did not result in concomitant mineralization or destruction of the FQ core.

According to bioassays and EEM-PARAFAC results, photolysis of ENR does not result in destruction of the FQ core, therefore keeping its antibacterial activity. In contrast, ( solar photo)-Fenton processes are able to destroy the FQ core, what results in a decrease of the inhibition halo.

Finally, EEM-PARAFAC study has demonstrated to be a simple methodology to provide supplementary information on the behaviour of organic matter and can be more easily correlated than HPLC analysis with changes in toxicity, and could be an alternative to sophisticated analytical techniques when identification of reaction by-products is not required.

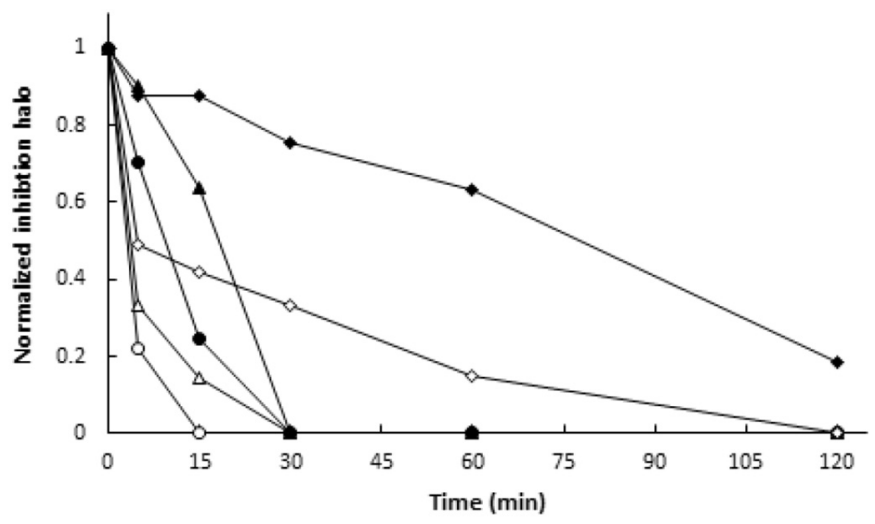

Fig. 8. Antibacterial activity behaviour obtained with solar photo-Fenton within the different tested water matrices. SW at $\mathrm{pH}=5(\diamond)$; $\mathrm{SW}$ at $\mathrm{pH}=2.8(\diamond) ; \mathrm{TW}$ at $\mathrm{pH}=5$ $(\Delta)$; TW at $\mathrm{pH}=2.8(\Delta) ; \mathrm{MQ}$ at $\mathrm{pH}=5(\bullet)$ and $\mathrm{MQ}$ at $\mathrm{pH}=2.8(\mathrm{O})$.

\section{Declaration of competing interest}

The authors declare that they have no known competing financial interests or personal relationships that could have appeared to influence the work reported in this paper.

\section{Acknowledgements}

This paper is part of a project that has received funding from the European Union's Horizon 2020 - Research and Innovation Framework Programme under the H2020 Marie Skłodowska-Curie Actions grant agreement No 765860. The paper reflects only the authors' view and the Agency is not responsible for any use that may be made of the information it contains.

\section{Appendix A. Supplementary data}

Supplementary data to this article can be found online at https://doi. org/10.1016/j.scitotenv.2020.137331.

\section{References}

Alves, J.C.L., Poppi, R.J., 2013. Simultaneous determination of hydrocarbon renewable diesel, biodiesel and petroleum diesel contents in diesel fuel blends using near infrared (NIR) spectroscopy and chemometrics. Analyst 138, 6477-6487. https://doi.org/ 10.1039/c3an00883e.

An, T., Yang, H., Li, G., Song, W., Cooper, W.J., Nie, X., 2010. Kinetics and mechanism of advanced oxidation processes (AOPs) in degradation of ciprofloxacin in water. Appl. Catal. B Environ. 94, 288-294. https://doi.org/10.1016/j.apcatb.2009.12.002.

Aresta, A., Cotugno, P., Zambonin, C., 2019. Determination of ciprofloxacin, enrofloxacin, and marbofloxacin in bovine urine, serum, and milk by microextraction by a packed sorbent coupled to ultra-high performance liquid chromatography. Anal. Lett. 52, 790-802. https://doi.org/10.1080/00032719.2018.1496093.

Aristilde, L., Melis, A., Sposito, G., 2010. Inhibition of photosynthesis by a fluoroquinolone antibiotic. Environ. Sci. Technol. 44, 1444-1450. https://doi.org/10.1021/es902665n.

Aufartová, J., Brabcová, I., Torres-Padrón, M.E., Solich, P., Sosa-Ferrera, Z., SantanaRodríguez, J.J., 2017. Determination of fluoroquinolones in fishes using microwaveassisted extraction combined with ultra-high performance liquid chromatography and fluorescence detection. J. Food Compos. Anal. 56, 140-146. https://doi.org/ 10.1016/j.jfca.2016.12.012

Babić, S., Periša, M., Škorić, I., 2013. Photolytic degradation of norfloxacin, enrofloxacin and ciprofloxacin in various aqueous media. Chemosphere 91, 1635-1642. https:// doi.org/10.1016/j.chemosphere.2012.12.072.

Bernabeu, A., Vercher, R.F., Santos-Juanes, L., Simón, P.J., Lardín, C., Martínez, M.A., Vicente, J.A., González, R., Llosá, C., Arques, A., Amat, A.M., 2011. Solar photocatalysis as a tertiary treatment to remove emerging pollutants from wastewater treatment plant effluents. Catal. Today 161, 235-240. https://doi.org/10.1016/j.cattod.2010.09.025.

Boughattas, F., Le Fur, B., Karoui, R., 2019. Non-targeted identification of brine covered canned tuna species using front-face fluorescence spectroscopy combined with chemometric tools. Food Anal. Methods 12, 2823-2834. https://doi.org/10.1007/s12161019-01638-w.

Bro, R., 1997. PARAFAC. Tutorial and applications. Chemom. Intell. Lab. Syst. 38, 149-171. https://doi.org/10.1016/S0169-7439(97)00032-4.

Bro, R., Kiers, H.A.L., 2003. A new efficient method for determining the number of components in PARAFAC models. J. Chemom. 17, 274-286. https://doi.org/10.1002/cem.801.

Buschmann, A.H. Tomova, A López A Maldonado, M.A. Henríquez, LA Ivanova, L. Moy, F., Godfrey, H.P., Cabello, F.C., 2012. Salmon aquaculture and antimicrobial resistance in the marine environment. PLoS One 7, 26-28. https://doi.org/10.1371/journal.pone.0042724.

Buxton, G.V., Greenstock, C.L., Helman, W.P., Ross, A.B., 1988. Critical Review of rate constants for reactions of hydrated electrons, hydrogen atoms and hydroxyl radicals $\left(\cdot \mathrm{OH} / \cdot \mathrm{O}^{-}\right)$in Aqueous Solution. J. Phys. Chem. Ref. Data 17, 513-886. https://doi. org/10.1063/1.555805.

Calza, P., Maurino, V., Minero, C., Pelizzetti, E., Sega, M., Vincenti, M., 2005. Photoinduced halophenol formation in the presence of iron(III) species or cadmium sulfide. J. Photochem. Photobiol. A Chem. 170, 61-67. https://doi.org/10.1016/j. jphotochem.2004.07.003.

Carabajal, M.D., Arancibia, J.A., Escandar, G.M., 2017. Excitation-emission fluorescencekinetic data obtained by Fenton degradation. Determination of heavy-polycyclic aromatic hydrocarbons by four-way parallel factor analysis. Talanta 165, 52-63. https:// doi.org/10.1016/j.talanta.2016.12.030.

Chen, Y., Wang, A., Zhang, Y., Bao, R., Tian, X., Li, J., 2017. Electro-Fenton degradation of antibiotic ciprofloxacin (CIP): formation of Fe3+-CIP chelate and its effect on catalytic behavior of $\mathrm{Fe} 2+/ \mathrm{Fe} 3+$ and CIP mineralization. Electrochim. Acta 256, 185-195. https://doi.org/10.1016/j.electacta.2017.09.173.

Cory, R.M., McKnight, D.M., 2005. Fluorescence spectroscopy reveals ubiquitous presence of oxidized and reduced quinones in dissolved organic matter. Environ. Sci. Technol. 39, 8142-8149. https://doi.org/10.1021/es0506962. 
Cuprys, A., Pulicharla, R., Brar, S.K., Drogui, P., Verma, M., Surampalli, R.Y., 2018. Fluoroquinolones metal complexation and its environmental impacts. Coord. Chem. Rev. 376, 46-61. https://doi.org/10.1016/j.ccr.2018.05.019.

De la Peña, A.M., Mansilla Espinosa, A., Gómez González, D., Olivieri, A.C., Goicoechea, H.C., 2003. Interference-free analysis using three-way fluorescence data and the parallel factor model. Determination of fluoroquinolone antibiotics in. Anal. Chem. 75, 2640-2646. https://doi.org/10.1021/ac026360h.

De Laat, J., Le, T.G., 2006. Effects of chloride ions on the iron(III)-catalyzed decomposition of hydrogen peroxide and on the efficiency of the Fenton-like oxidation process. Appl. Catal. B Environ. 66, 137-146. https://doi.org/10.1016/j.apcatb.2006.03.008.

De Luca, A., Dantas, R.F., Esplugas, S., 2014. Assessment of iron chelates efficiency forphoto-Fenton at neutral pH. Water Res. 61, 232-242. https://doi.org/10.1016/j. watres.2014.05.033.

Ebert, I., Bachmann, J., Kühnen, U., Küster, A., Kussatz, C., Maletzki, D., Schlüter, C., 2011. Toxicity of the fluoroquinolone antibiotics enrofloxacin and ciprofloxacin to photoautotrophic aquatic organisms. Environ. Toxicol. Chem. 30, 2786-2792. https://doi.org/ 10.1002/etc.678.

ECDC/EFSA/EMA, 2017. ECDC/EFSA/EMA second joint report on the integrated analysis of the consumption of antimicrobial agents and occurrence of antimicrobial resistance in bacteria from humans and food-producing animals. EFSA J., 15 https://doi.org/ 10.2903/j.efsa.2017.4872.

Efthimiadou, E.K., Karaliota, A., Psomas, G., 2008. Mononuclear metal complexes of the second-generation quinolone antibacterial agent enrofloxacin: synthesis, structure, antibacterial activity and interaction with DNA. Polyhedron 27, 1729-1738. https:// doi.org/10.1016/j.poly.2008.02.006.

Feng, M., Wang, X., Chen, J., Qu, R., Sui, Y., Cizmas, L., Wang, Z., Sharma, V.K., 2016. Degradation of fluoroquinolone antibiotics by ferrate(VI): effects of water constituents and oxidized products. Water Res. 103, 48-57. https://doi.org/10.1016/j. watres.2016.07.014.

Feng, M., Wang, Z., Dionysiou, D.D., Sharma, V.K., 2018. Metal-mediated oxidation of fluoroquinolone antibiotics in water: a review on kinetics, transformation products, and toxicity assessment. J. Hazard. Mater. 344, 1136-1154. https://doi.org/10.1016/j. jhazmat.2017.08.067.

García Ovando, H., Gorla, N., Luders, C., Poloni, G., Errecalde, C., Prieto, G., Puelles, I., 1999. Comparative pharmacokinetics of enrofloxacin and ciprofloxacin in chickens. J. Vet. Pharmacol. Ther. 22, 209-212. https://doi.org/10.1046/j.1365-2885.1999.00211.x.

García-Ballesteros, S., Mora, M., Vicente, R., Vercher, R.F., Sabater, C., Castillo, M.A., Amat, A.M., Arques, A., 2019. A new methodology to assess the performance of AOPs in complex samples: application to the degradation of phenolic compounds by $\mathrm{O} 3$ and 03/UV-A-Vis. Chemosphere 222, 114-123. https://doi.org/10.1016/j. chemosphere.2019.01.015.

García-Ballesteros, S., Mora, M., Vicente, R., Sabater, C., Castillo, M.A., Arques, A., Amat, A.M., 2016. Gaining further insight into photo-Fenton treatment of phenolic compounds commonly found in food processing industry. Chem. Eng. J. 288, 126-136. https://doi.org/10.1016/j.cej.2015.11.031

Ge, L., Chen, J., Xiaoxuan, W., Zhang, S., Qiao, X., Xiyun And, C., Qing, X., 2010. Aquatic photochemistry of fluoroquinolone antibiotics: kinetics, pathways, and multivariate effects of main water constituents. Environ. Sci. Technol. 44, 2400-2405. https://doi. org/10.1021/es902852v.

Ge, L., Na, G., Zhang, S., Li, K., Zhang, P., Ren, H., Yao, Z., 2015. New insights into the aquatic photochemistry of fluoroquinolone antibiotics: direct photodegradation, hydroxylradical oxidation, and antibacterial activity changes. Sci. Total Environ. 527-528, 12-17. https://doi.org/10.1016/j.scitotenv.2015.04.099.

Ge, L., Halsall, C., Chen, C.E., Zhang, P., Dong, Q., Yao, Z., 2018. Exploring the aquatic photodegradation of two ionisable fluoroquinolone antibiotics - gatifloxacin and balofloxacin: degradation kinetics, photobyproducts and risk to the aquatic environment. Sci. Total Environ. 633, 1192-1197. https://doi.org/10.1016/j.scitotenv.2018.03.279.

Giri, A.S., Golder, A.K., 2019. Ciprofloxacin degradation in photo-Fenton and photocatalytic processes: degradation mechanisms and iron chelation. J. Environ. Sci. (China) 80, 82-92. https://doi.org/10.1016/j.jes.2018.09.016.

Glaze, W.H., Kang, J., Douglas, H., 1987. The chemistry of water treatment processes involving ozone, hydrogen peroxide and ultraviolet radiation. Ozone Sci. Eng., 335-352 https://doi.org/10.1080/01919518708552148.

Gomis, J., Bianco Prevot, A., Montoneri, E., González, M.C., Amat, A.M., Mártire, D.O., Arques, A., Carlos, L., 2014. Waste sourced bio-based substances for solar-driven wastewater remediation: photodegradation of emerging pollutants. Chem. Eng. J. 235, 236-243. https://doi.org/10.1016/j.cej.2013.09.009.

Gomis, J., Gonçalves, M.G., Vercher, R.F., Sabater, C., Castillo, M.A., Prevot, A.B., Amat, A.M., Arques, A., 2015. Determination of photostability, biocompatibility and efficiency as photo-Fenton auxiliaries of three different types of soluble bio-based substances (SBO). Catal. Today 252, 177-183. https://doi.org/10.1016/j.cattod.2014.10.015.

Guinea, E., Brillas, E., Centellas, F., Cañizares, P., Rodrigo, M.A., Sáez, C., 2009. Oxidation of enrofloxacin with conductive-diamond electrochemical oxidation, ozonation and Fenton oxidation. A comparison. Water Res. 43, 2131-2138. https://doi.org/ 10.1016/j.watres.2009.02.025.

Gupta, A., Garg, A., 2018. Degradation of ciprofloxacin using Fenton's oxidation: effect of operating parameters, identification of oxidized by-products and toxicity assessment. Chemosphere 193, 1181-1188. https://doi.org/10.1016/j.chemosphere.2017.11.046.

Hamad, B., 2010. The antibiotics market. Nat. Rev. Drug Discov. 9, 675-676. https://doi. org/10.1038/nrd3267.

He, X., Wang, Z., Nie, X., Yufen, Yang, Pan, D., Leung, A.O.W., Cheng, Z., Yongtao, Yang, Li, K., Chen, K., 2012. Residues of fluoroquinolones in marine aquaculture environment of the Pearl River Delta, South China. Environ. Geochem. Health 34, 323-335. https://doi.org/10.1007/s10653-011-9420-4.

Idowu, O.R., Peggins, J.O., 2004. Simple, rapid determination of enrofloxacin and ciprofloxacin in bovine milk and plasma by high-performance liquid chromatography with fluorescence detection. J. Pharm. Biomed. Anal. 35, 143-153. https://doi.org/ 10.1016/j.jpba.2004.01.006

Karoui, R., De Baerdemaeker, J., 2007. A review of the analytical methods coupled with chemometric tools for the determination of the quality and identity of dairy products. Food Chem. 102, 621-640. https://doi.org/10.1016/j.foodchem.2006.05.042.

Legrini, O., Oliveros, E., Braun, A.M., 1993. Photochemical processes for water treatment Chem. Rev. 93, 671-698. https://doi.org/10.1021/cr00018a003.

Li, Y., Niu, J., Wang, W., 2011. Photolysis of Enrofloxacin in aqueous systems under simulated sunlight irradiation: kinetics, mechanism and toxicity of photolysis products. Chemosphere 85, 892-897. https://doi.org/10.1016/j.chemosphere.2011.07.008.

Li, X., Dai, X., Takahashi, J., Li, N., Jin, J., Dai, L., Dong, B., 2014. New insight into chemica changes of dissolved organic matter during anaerobic digestion of dewatered sewage sludge using EEM-PARAFAC and two-dimensional FTIR correlation spectroscopy Bioresour. Technol. 159, 412-420. https://doi.org/10.1016/j.biortech.2014.02.085.

Liu, H., Zhao, H., Quan, X., Zhang, Y., Chen, S., 2009. Formation of chlorinated intermediate from bisphenol A in surface saline water under simulated solar light irradiation. Environ. Sci. Technol. 43, 7712-7717. https://doi.org/10.1021/es900811c.

Lizondo, M., 1997. Physicochemical properties of. J. Food Lipids 16, 540-553. https://doi. org $/ 10.1691 / \mathrm{ph} .2008 .7308$.

Ly, Q.V., Kim, H.C., Hur, J., 2018. Tracking fluorescent dissolved organic matter in hybrid ultrafiltration systems with TiO2/UV oxidation via EEM-PARAFAC. J. Membr. Sci. 549, 275-282. https://doi.org/10.1016/j.memsci.2017.12.020.

Machulek Amilcar, J., Moraes Jose, E.F., Vautier-Giongo, C., Silverio Cristina, A., Friedrich Leidi, C., Nascimento Claudio, A.O., Gonzalez Monica, C., Quina Frank, H., 2007. Abatement of the inhibitory effect of chloride anions on the photo-Fenton process. Environ. Sci. Technol. 41, 8459-8463. https://doi.org/10.1021/es071884q.

Malato, S., Fernández-Ibáñez, P., Maldonado, M.I., Blanco, J., Gernjak, W., 2009. Decontamination and disinfection of water by solar photocatalysis: recent overview and trends. Catal. Today 147, 1-59. https://doi.org/10.1016/j.cattod.2009.06.018.

Michael, I., Hapeshi, E., Aceña, J., Perez, S., Petrović, M., Zapata, A., Barceló, D., Malato, S. Fatta-Kassinos, D., 2013. Light-induced catalytic transformation of ofloxacin by solar Fenton in various water matrices at a pilot plant: mineralization and characterization of major intermediate products. Sci. Total Environ. 461-462, 39-48. https://doi.org/ 10.1016/j.scitotenv.2013.04.054.

García-ballesteros, S., Micó, P., Mora, M., Vicente, R., Amat, A.M., Arques, A., 2019. EEMlab: a graphical user-friendly interface for fluorimetry experiments based on the drEEM toolbox. Chemom. Intell. Lab. Syst. 188, 6-13. https://doi.org/10.1016/j. chemolab.2019.03.001.

Murphy, K.R., Stedmon, C.A., Graeber, D., Bro, R., 2013. Fluorescence spectroscopy and multi-way techniques. PARAFAC. Anal. Methods 5, 6557-6566. https://doi.org/ 10.1039/c3ay41160e.

Ni, Y., Du, S., Kokot, S., 2009. Molecular spectroscopy and chemometrics: an analytical study of synergistic effects of drugs - interaction between fluoroquinolones and DNA. Analyst 134, 1840-1847. https://doi.org/10.1039/b904018h.

Nogueira, R.F.P., Oliveira, M.C., Paterlini, W.C., 2005. Simple and fast spectrophotometric determination of $\mathrm{H} 2 \mathrm{O} 2$ in photo-Fenton reactions using metavanadate. Talanta 66 , 86-91. https://doi.org/10.1016/j.talanta.2004.10.001.

Pignatello, J.J., 1992. Dark and photo assisted Fe3+ catalyzed degradation of chlorophenoxy herbicides by hydrogen peroxide. Environ. Sci. Technol 26, 944-951. https://doi.org/10.1021/es00029a012.

Pignatello, J.J., Oliveros, E., MacKay, A., 2006. Advanced oxidation processes for organic contaminant destruction based on the Fenton reaction and related chemistry. Crit. Rev. Environ. Sci. Technol. 36, 1-84. https://doi.org/10.1080/10643380500326564.

Rakshit, S., Sarkar, D., Elzinga, E.J., Punamiya, P., Datta, R., 2013. Mechanisms of ciprofloxacin removal by nano-sized magnetite. J. Hazard. Mater. 246-247, 221-226. https:// doi.org/10.1016/j.jhazmat.2012.12.032.

Robinson, A.A., Belden, J.B., Lydy, M.J., 2005. Toxicity of fluoroquinolone antibiotics to aquatic organisms. Environ. Toxicol. Chem. 24, 423-430. https://doi.org/10.1897/ 04-210R.1.

Rosen, T., Shen, L.L., O’Donnell, T.J., Chu, D.W.T., Cooper, C.S., Pernet, A.G., Mitscher, L.A Sharma, P.N., 1989. Mechanism of inhibition of DNA gyrase by quinolone antibacterials: a cooperative drug-DNA binding model. Biochemistry 28, 3886-3894. https:// doi.org/10.1021/bi00435a039.

Santos-Juanes, L., Amat, A.A., Arques, A., 2017. Strategies to drive photo-Fenton process at mild conditions for the removal of xenobiotics from aqueous systems. Curr. Org. Chem. 21, 1074-1083. https://doi.org/10.2174/1385272821666170102150337.

Soler, J., García-Ripoll, A., Hayek, N., Miró, P., Vicente, R., Arques, A., Amat, A.M., 2009. Effect of inorganic ions on the solar detoxification of water polluted with pesticides. Water Res. 43, 4441-4450. https://doi.org/10.1016/j.watres.2009.07.011.

Stedmon, C.A., Markager, S., Bro, R., 2003. Tracing dissolved organic matter in aquatic environments using a new approach to fluorescence spectroscopy. Mar. Chem. 82 239-254. https://doi.org/10.1016/S0304-4203(03)00072-0.

Sun, Y., Cho, D.W., Graham, N.J.D., Hou, D., Yip, A.C.K., Khan, E., Song, H., Li, Y., Tsang, D.C.W., 2019. Degradation of antibiotics by modified vacuum-UV based processes: mechanistic consequences of $\mathrm{H} 2 \mathrm{O} 2$ and K2S2O 8 in the presence of halide ions. Sci. Total Environ. 664, 312-321. https://doi.org/10.1016/j.scitotenv.2019.02.006.

Tang, J., Wang, W., Yang, L., Qiu, Q., Lin, M., Cao, C., Li, X., 2020. Seasonal variation and ecological risk assessment of dissolved organic matter in a peri-urban critical zone observatory watershed. Sci. Total Environ. 707, 136093. https://doi.org/10.1016/j. scitotenv.2019.136093.

Trawiński, J., Skibiński, R., 2018. Photolytic and photocatalytic transformation of an antipsychotic drug asenapine: comparison of kinetics, identification of transformation products, and in silico estimation of their properties. Ecotoxicol. Environ. Saf. 162, 272-286. https://doi.org/10.1016/j.ecoenv.2018.07.010.

Turel, I., 2002. The interactions of metal ions with quinolone antibacterial agents. Coord. Chem. Rev. 232, 27-47. https://doi.org/10.1016/S0010-8545(02)00027-9. 
Van Doorslaer, X., Demeestere, K., Heynderickx, P.M., Caussyn, M., Van Langenhove, H., Devlieghere, F., Vermeulen, A., Dewulf, J., 2013. Heterogeneous photocatalysis of moxifloxacin: identification of degradation products and determination of residual antibacterial activity. Appl. Catal. B Environ. 138-139, 333-341. https://doi.org/ 10.1016/j.apcatb.2013.03.011.

Van Doorslaer, X., Dewulf, J., Van Langenhove, H., Demeestere, K., 2014. Fluoroquinolone antibiotics: an emerging class of environmental micropollutants. Sci. Total Environ. 500-501, 250-269. https://doi.org/10.1016/j.scitotenv.2014.08.075.

Villegas-Guzman, P., Oppenheimer-Barrot, S., Silva-Agredo, J., Torres-Palma, R.A., 2017. Comparative evaluation of photo-chemical AOPs for ciprofoxacin degradation: elimination in natural waters and analysis of $\mathrm{pH}$ effect, primary degradation by-products, and the relationship with the antibiotic activity. Water Air Soil Pollut. 228, 209-224. https://doi.org/10.1007/s11270-017-3388-3.

Vosough, M., Eshlaghi, S.N., Zadmard, R., 2015. On the performance of multiway methods for simultaneous quantification of two fluoroquinolones in urine samples by fluorescence spectroscopy and second-order calibration strategies. Spectrochim. Acta A Mol. Biomol. Spectrosc. 136, 618-624. https://doi.org/10.1016/j.saa.2014.09.075.

Zhang, Z., Xie, X., Yu, Z., Cheng, H., 2019. Influence of chemical speciation on photochemical transformation of three fluoroquinolones (FQs) in water: kinetics, mechanism, and toxicity of photolysis products. Water Res. 148, 19-29. https://doi.org/10.1016/ j.watres.2018.10.027. 